\title{
A STUDY ON THE EFFECT OF MULTILINGUAL REPERTOIRE ON SPEAKING IN THREE UNIVERSITIES IN METRO CITY, LAMPUNG - INDONESIA
}

\author{
Nurul Aini \\ Universitas Nahdatul Ulama, Lampung \\ E-mail: aininurul92@gmail.com
}

\begin{abstract}
In the whole part of the world, some people could speak more than two languages. This phenomenon is called by Multilingual Repertoire. Multilingual Repertoire in the students of PBI in IAIN Metro, Muhammadiyah University, and IAIM NU Metro greatly effects to the students' speaking, especially in pronunciation, style, grammar, and vocabularies. Therefore, this research attempts to know the effect of students' multilingual repertoire in speaking English. The learners' subject in this research is 15 students in English language program from three universities in Metro. Method of this research is qualitative. The data was achieved through several techniques, they are: observation, interview, and documentation. The data will be achieved through Focus Group Discussion (FGD), interview, and observation. The examination of the collected data reveals that $40 \%$ of the students are able to speak English, but they speak in Javanese dialect and style, $20 \%$ of the students speak in Sundanese style, $13 \%$ of the students speak in Lampungnese style, $13 \%$ of the students speak in Padangnese style, $7 \%$ of the students speak in Melayu style, and the rest is $7 \%$ of the students speak in Balinese style. Meanwhile, some of the students need a repetition in speaking skill to make it clear and with makes some grammatical errors. In this regard, the students should be careful in grammatical of each language when they are speaking.
\end{abstract}

Keywords: Local Languages, Multilingualism, Multilingual Repertoire, Speaking.

\section{INTRODUCTION}

Indonesia has long history of globalization for which the development of multilingual society has inevitable. In such a globalized region, a multilingual society has been developed due to migration, cultural contact, and commerce. Then, the circumstances of language system in Indonesia will be changed from mastering of two languages (bilingual) to be three languages (multilingual)(Putu and Rohmadi, 2010:56).

In the last ten years, many researchers have research the use of multilingual repertoire in writing. They have analyzed how multilingual repertoire has influenced the students' multilingual repertoire or autism writing using some strategies. Most studies explain that many people have gained the multilingual repertoire through the process of their reading and writing tradition they have developed (e.g. Jacobs, 2008; Cihon, 2007; Zacharias, 2012; Bedamatta, 2013; Ludi, 2003; Ehsanzadeh, 2012; Haque, 2011). Most others explain the multilingual repertoire in autism information development about the formal language effectively (e.g. Carbone, 2010; Emily, 2007; Cobb, 2002; Lee, 2005; Helderman, 2006). Most of them focus on multilingual 
repertoire by the learners or autism writing product.

Jacobs (2008) analyzes Instant Messaging (IM) in the students' repertoire development. Next, Cihon (2007) emphasizes some methods and strategies which involve individual behavior in learning intra verbal repertoire by precision teaching (PT) response. Zacharias (2012) indicates to what extent the increasing of 30 students in the process of English language learning as the foreign language as well as learn about the west culture. Bedamatta (2013) concerns on multilingual education in teaching learning process through mother tongue and second language. Ludi (2003) describes the usage of multilingual repertoire in the context of communication inter culture in the society. Ehsanzadeh (2012) defines some technique to improve the students' vocabulary by using the lexical repertoire in reading. Haque (2011) concerns that in language practices based on the Immigrant society in India. The purpose is to know to what extent of the individual repertoire based on the context of immigrant society in India.

The aims of this research are; first, to observe the factors of multilingual repertoire effect in speaking. Second, to find the field description of the reasoning based on advantages multilingual repertoire in the PBI students at three universities. Third, to investigate the field phenomena of the pronunciation and grammar errors in speaking based on multilingual students.An individual multilingual repertoire gives a great effect toward the students' speaking skill in English language learning.

\section{Multilingualism}

In many parts of the Western world is often assumed that it to be a world-wide phenomenon, to the extent that bilingual and multilingual individuals may appear to be unusual. The effect of this phenomenon is such people are likely to be immigrants, visitors, or children of mixed marriages. As a result some people is fluent in several languages although they are not the real native of that language (Wardaugh, 2006: 96).

Nowadays, the fact that there are 3.000 to 4.000 languages spoken in the world. In other words, the fact that there are about 150 countries indicates how multilingual applied in the societies (Carol, 1988: 51). Multilingualism is the best way to identify a person by his or her language, because language is one of identity of people. Therefore, the studying of two or more languages thus provides a rich field for sociolinguistics study (Spolsky, 1998: $51)$.

\section{Multilingual Repertoire}

In multilingual countries there is enough evidence of a child growing up with two or more languages. Even in dominant monolingual countries such instances are not rare. Hymes (in Haque 2011) argues that repertoire as a set of ways of speaking which consist of speech style and context. Multilingual repertoire phenomena which commonly happen in the society is effect of the individual languages. Many reasons make one mastering the repertoire in his life. The first reason is to implement freely communication. For generally, language practices of a group of people who have an opportunity to interact and share not just a single language is able to build a close relation of each other (Spolsky, 1998: 25).

Recently, multiculturalism in Indonesia leads us to the multilingual society. Thus, multilingual repertoire occur in many aspects, they are; in education, entertainment, and daily lives. Specifically, 
multilingual repertoire is not only useful things, but also an over plus skill for someone. Multilingual repertoire can be regarded as an important phenomenon in this globalized era. The intricacies of the multilingual repertoire learners' are often the results of interference from the previous learned languages of spelling, pronunciation and grammar.

In Indonesia, the students are seldom speak English orally as their communicative interaction in society. Because the student sometimes mispronounce words such as determine and bought, which are respectively incorrectly pronounced as [dit3: rmain] and [baut]. The students predictably make grammatical errors such as in the formation of yes no question and degrees of comparisons for adjectives or adverbs. The students might produce phrase more largebecause they find that the comparison forms for the adjectives beautiful is more beautiful (Alip, 2003).

Therefore, Annamalaiin (Haque, 2011: 29) examines that the languages not to be in conflict with an individual identity. But, one language is for ethnic identity, another for business transactions, for official dealings, for entertainment, for rituals and so on.

\section{Speaking}

Speaking tends to be getting something done, exploring ideas, working out of the world, or simply being together (Jones, 1996: 12). People can improve the fluency and the power of the speech by practicing. Pronunciation is also the important things. Because pronunciation is the act of articulating a sound or word (Brown, 2001: 267).The listener can understand the meaning of the word that the speakers says. In teaching speaking, the teacher hopes that the students can practice the pronunciation in the class. By this, the teacher knows the students speaking ability.

Some roles to speak well are read, listen, think and practice. Then, in speaking, commonly people have some problems in their speaking performance which called by error. On the other hand, error is something in a piece of work that is incorrect which cause problems or effect the result of something, something unintentionally done wrong as a result of poor judgment, an opinion or believe that is contrary to factor to establish doctrine.

Lead to speaking, some of errors may occur in pronunciation, spelling, morphology, syntax, and semantics. In the grammatical analysis there are some classification of errors which consider in language, by the classification, it can see the error of grammar usage and know the specific of error.

\section{Sentence}

Sentence is largest purely grammatical unit in a language. Indeed, there are larger linguistic units than sentences. That is paragraphs, conversations and discourses. In spite of that, these are not stronger linked by purely grammatical means (Peter, 2007: 257).Instead, sentence is the rigid grammatical rules which integrates the largest linguistic unit. In most linguists' perspectives, a sentence is an abstract linguistic object and it particularly puts together entirely in accordance with the rules for constructing sentences in a language.

As the example, sentence colorless green ideas sleep furiously, it makes no sense at all, it is constructed in accordance with all the rules for making sentences in English, and hence it is a grammatical (well-formed) sentence of English. A 
further point is that a sentence is not just a string of words rather than a grammatical (syntactic) structure assigned to it (Peter, 2007: 258).

The essential difference between sentences and utterances is that sentences are abstract, not tied to contexts, whereas utterances are identified by their contexts. The essential difference between sentences and utterances is that sentences are abstract, not tied to contexts, whereas utterances are identified by their contexts. This is also the main way of distinguishing between semantics and pragmatics. In other words, semantics deals with meaning and there is no context to consider. Nevertheless, if there is a context to be brought into consideration means that it engages in pragmatics (Peter, 2007: 6).

A sentence with more than two structural interpretations is said to be multiply ambiguous. An analysis which demonstrates the ambiguity in a sentence is said to disambiguate the sentence. Ambiguity which does not arise from the grammatical analysis of a sentence, but is due solely to the alternative meanings of an individual lexical item, is referred to as lexical ambiguity, e.g. I found the table fascinating (='object of furniture' or 'table of figures' - see polysemy). How the brain resolves ambiguities is an important goal of psycholinguistic research.The meaningful parts ofa sentence are clauses, phrases and words; and the meaningful parts ofwords are morphemes.

\section{METHOD}

Here, the participants have been chosen from the students of English Education Study Program that had learned sociolinguistics subject and have different ethnics in Universities of Metro. There were 15 consisting of 10 females and 5 males. Most of them were in eight semester and others are in sixth semester. In this case, the students' abilities in speaking English were low and high because of the effect of their local languages.

The ethnic languages that analyzed are Javanese, Lampungnese, Padangnese, Balinese, Sundanese and Melayu. By this, 5 students are Javanese, 2 Lampungnese, 3 Padangnese, 1 Balinese, 3 Sundanese and Melayu. Their multilingual repertoire influence their speaking skill, especially in grammar, phonetic and phonology.

Actually, this research is qualitative. Creswell (2003: 182) defines that the researcher made interpretation of the data. There are two kinds of data sources, namely primaryand secondary sources (Ary, 2006: 482). The primary source in this research is the students' speaking product. Then, the secondary source is from books, articles, English dictionary, encyclopedia, and journals that are closely related to the research.

The data was achieved through several techniques, they are: observation, interview, and documentation. After getting all the data, Creswell (2003: 184) states that in many qualitative studies, inquiries collect multiple forms of data and send a considerable time in the natural setting gathering information. The data also were collected by applying Focus Group Discussion (FGD). Here, it not use natural setting but conditional setting.

In this study use purposive sample to identify the purposefully selected participants for the purpose studies that will help to understand the problem and the research questions. It has chosen the students of English Education Study Program that had learned sociolinguistics subject and have different ethnics in Universities of Metro as the participants. 


\section{Result of Focus Group Discussion}

In this case, the students were analyzed by their speaking. These are four topics such as personal experiences, disasters, legends, and fables. The aspects were analyzed such as the effect from dialect, the grammar errors in students speaking skill, and the contribution of ethnic language in cultural style and code switching based on the students' speaking skill.

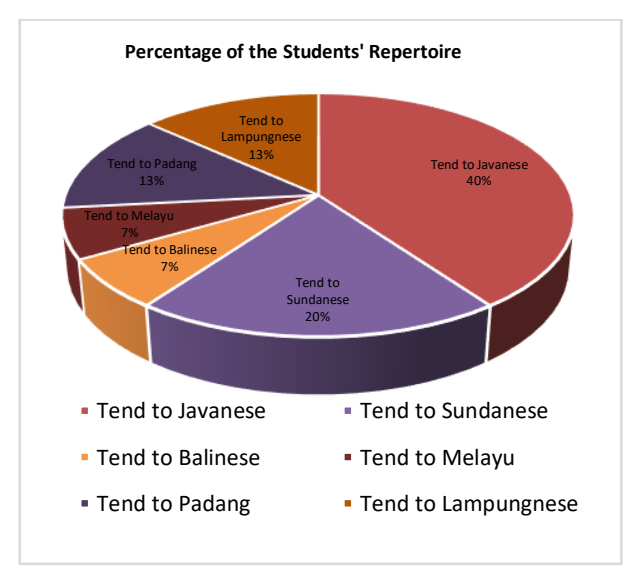

Figure I. The effect of students multilingual repertoire in dialect of speaking English.

Based on the above data, it would be describe that:

There are 6 students who speak English fluently by using their Javanese dialect. They tend to speak English in Javanese style such as when they pronounce speak with sepik, and school with sekul. Then, 3 students who speak English fluently by using their Sundanese dialect. They speak Good Morning in a Sundanese style, but they tend to use an Indonesian dialect. Next, 1 student who speaks English fluently by using Balinese dialect. That student pronounce the word like a native and fast, but still use Balinese style like intonation and pronunciation. It is such long long time ago with lung lung time ago and the clear intonation. The other student is 1 student who speaks English use Melayu style. The finding that the students tend to use Melayu pronunciation like "e" when speaking English such as since I in Lampung with sence I in Lampung.Then, 2 students who speak English by using Padangnese dialect and style. They tend to speak English with Indonesian style and dialect, but sometimes they still use their own dialect like "o", example: disaster about with disosterebout. Last, 2 students who speak English by using Lampungnese dialect and style. Then, found that they tend to Indonesia like Sundanese and Padangnese. Sometimes they use loudly intonation like in Lampungnese.

\section{The grammar errors in students speaking skill}

Some students in three universities of Metro made a number of mistakes in grammar. The disadvantages will be discussed below:

\section{Word order}

a. I can speak Javanese language.

b. I can speak Indonesian language.

c. I could life in this world until this day.

d. It is good my planning.

Most of the above sentences are use unsuitable word in accomplishing the sentences. In the first sentence is incorrect because Javanese is language of Java. It would be better to speak Javanese without language. Then, the last sentence shown inappropriate word. The word "day" is not followed by "this" but "to". The correct word is today.

\section{Modal Auxiliary}

a. I thought about what have I done.

b. I could life in this world until this day.

c. I would got many experiences. 
d. I can met the people from Sabang until Merauke.

e. We can took conclusion.

The description of all the above sentences are modal auxiliary must be putted after the subject and always followed by verb base. Then, modal auxiliary must be followed verb. Thus, modal auxiliary was not followed by noun, adverb, and adjectives.

\section{Noun}
a. Some kind of food.
b. I got a new friends.
c. I can speak very little about Javanese.
d. ... And then little little about Javanese.
e. I got many friend from other Island.
f. In Lampung, so many thing is so cheap.

Based on the above sentences can be seen that was unsuitable form, because some always followed by plural form. Then, the other sentence used singular form but followed by plural form. By this, the correct sentences are some kinds of foodsand I got a new friend.

In addition, little, many and some included in countable and uncountable classifying. Little must be spoken without repetition like the above sentences noticed by PBI students.

\section{Phrasal verb}

a. The people very different withothers.

Phrasal verb has the own couple of the current words. In this sentence is incorrect because the couple of different is from, to, and then.

\section{Degree of comparison}

a. I can speak Javanese more fluently. b. The beautifullist in Lampung is Krui beach.

Those sentences are inappropriate with the adjectives fluent and beautiful. The word fluent was not followed by more but change the function to be an adverb that is fluently. The next sentence is also unsuitable with the degree of comparison rules, because beautiful is one syllable. Therefore, before beautiful must put more.

\section{Preposition}

a. I was disappeared in under water.

Preposition is a word or a group of word such as in, from, under, to, and etc. The above sentence has two preposition those are in and under. The correct sentence is I was disappeared under water.

7. Verb

a. The title RoroJonggrang.

b. I register in Muhammadiyah University with my friend.

c. I am happy when I accepted in this University.

d. I very happy in Lampung.

e. I enjoying the heaven of Lampung.

f. I shopping in some markets.

The discussion of verb form are very complicated, because it use all of the tenses in establishing the sentence. Those sentences are inappropriate in the using of tenses form. The students want to tell about the past even but they always use present tenses.

\section{Conjunction}

a. And not only from Java, but it spared to another Island.

b. Beside it, I shopping in ...

In the first sentence shown that not only is not has appropriate couple. In this case, the couple of not only is but also. The 
second sentence known that beside as the conjunction was followed by $s$.

From the above discussion, it can be seen that there are some students' errors in many parts of structure and grammar as a result of their own multilingual repertoire. By this, we know that some students in three universities use their own repertoire to speak English.

\section{The contribution of ethnic language in cultural style and code switching based on the students' speaking skill}

In line with the data analysis, the researcher found several styles in students speaking performance. It can be assumed in percentage that $50 \%$ students in three universities use Indonesian style especially in Islamic culture. Some students in those universities are common to start their speaking with Basmallah and Salam then for the last they are common to say ok, I think that's all from me, the last I say, and ok, I think enough from me, then Salam.

On the other hand, most students are common to switch more than two languages in their speaking performance. For example are: you must manage your money well, yeah like saya, my friends from senior high school KartikatamasatuMetro, and the mother angry with him and mengutuk or mengcoach become a stone.

The result of the above description are multilingual repertoire give much effect in the students speaking performance. Those effect are through the students' style and code switching.

\section{Result of Observation and Interview}

Regarding with the result of observation and interview, the writer found two aspects such as the repetition in students speaking English and the advantages of the students' multilingual repertoire. The following explanations are bellow:

The repetition in students speaking English

All of the students in three universities are always doing repetition like "of course", "and then", "what is it", "and", "because", "after that", "well", "ok", and "in here". They use the same words to improve their idea such as "a", "ok", "well", and "yeah". In this case show that some of the students in three universities need repetition in their speaking to make the listener understand about the point of the topics.

\section{The advantages of the students' multilingual repertoire}

Regarding to the disadvantages of Multilingual Repertoire, it has some advantages in students' speaking skill. There were the advantages: 1) the students could know the other languages and cultures, and 2) the students were easily to communicate with others. Related to the discussion, the PBI students of three universities are enjoy the teaching learning process whether the teacher switch the language. On the other hand, the fluently in speaking is one of advantages from the students' Multilingual Repertoire.

\section{DISCUSSION}

The conclusion of data analysis describes that most students have their own repertoire. The students' repertoire are more than two languages which called by multilingual repertoire. The result of the data analysis that Javanese is the only ethnic which give a big effect in the students speaking performance. Those effect are through pronunciation, style, vocabularies, grammar, and comprehension. 
It is revealed that $40 \%$ students tend to Javanese, $20 \%$ students tend to Sundanese, $13 \%$ tend to Lampungnese, $13 \%$ tend to Padangnese, $7 \%$ tend to Melayu, and 7\% tend to Balinese. By conducting this research, we could know to what extent the effect of the students' multilingual repertoire in speaking English at three universities. Then, we can know how multilingual repertoire changes the students' style in speaking English. Last, the audio-visual method can be utilized as teaching aid in teaching speaking.

Based on the result of this research, the researcher realizes that this research is affirmative to the previous research from India named Shahzaman Haque. Haque conducted his research in three cities in India. Nevertheless, this research has uniqueness in collecting the data by using FGD for speaking skill. And conduct the research in three universities in Metro.

\section{CONCLUSION}

In many parts of the world, some people could speak more than two languages. This phenomenon is called by multilingual repertoire. Multilingual repertoire in the students of PBI in IAIN Metro, Muhammadiyah University, and IAIM NU Metro give great effects to the students speaking. Therefore, the researcher conduct this research by analyzing the effect of the students' multilingual repertoire on speaking performance.

In this research, found that there were $40 \%$ students have ability to speak English fluently, but they use Javanese dialect and style. Then, 20\% students tend to Sundanese, but the dialect is not give big effect in speaking. Next, $13 \%$ students tend to Lampungnese which the style is dominant. The other is $13 \%$ students tend to Padangnese, which the style is also dominant. Then, 7\% students tend to Melayu, and last is $7 \%$ student tend to Balinese. However, some students in those universities need a repetition in speaking performance to make it clear.

Finally, the effect of the students' multilingual repertoire in speaking is not only from dialect, but also from the students' ethnic style. The effect of dialect comes from others languages in pronunciation, grammar and vocabularies. Then, the effect of style comes from others languages in comprehension and cultural style.

\section{REFERENCES}

Abdul Chaer. (1995). Sosiolinguistik: PerkenalanAwal. Jakarta: RinekaCipta.

Albert. M, Kristin,et.al. (2012).Increasing the mand repertoire of children with autism through the use of an interrupted chain procedure, Carbone Clinic.

Alip, Francis Borgias. (2003). Historical Perspective in Learning English, Yokyakarta: Sanata Dharma University.

Anderson, R.C, \& Freebody, P. (1983).Reading comprehension and the assessment and acquisition of word knowledge. Greenwich: CT: JAI Press.

Ary ,Donal, et al. (2006). Introduction to Research In Education ( $7^{\text {th }}$ edition), Canada: Thompshon higher education.

Baron, N.S. (1984). "Computer Mediated Communication as a Force in Language Change". Visible 
Language. Vol. 18, No. 2, P. 118141.

Bedamatta, Urmishree. (2013). Playing with Nonsense: Toward Language Bridging in a Multilingual Classroom, London: Oxford University Press.

Brown, Douglas. (2001).Teaching by principles: An Interactive Approach to Language Pedagogy ( $2^{\text {th }}$ edition), San Francisco State University: Longman.

Carbone, Vincent. J. (2010). Increasing the vocal responses of children with autism and other developmental disabilities using manual sign mand training and prompt delay, Journal of Applied Behavior Analysis.

Cihon, Traci. M. (2007). A Review of Training Intra-verbal Repertoires: Can Precision Teaching Help? , Columbus: The Ohio State University.

Creswell, John W. (2003).Research design: Qualitative, Quantitative, and mixed methods approaches (2 ${ }^{\text {nd }}$ edition), New Delhi: Sage Publication.

Cobb, C. (2002). Kewl or 2 much, New York:Orlando Sentinel.

Cooper, J. (2005). Applied research: The separation of applied behavior analysis and precision teaching, Upper Saddle River, NJ: Prentice Hall/Merrill.

\section{Dewa Putu Wijana, et.al. (2010).Sosiolinguistik Kajian Teori}

dan Analisis. Yokyakarta: Pustaka Pelajar.

Ehsanzadeh, SayedJafar. (2012). Depth versus breadth of lexical repertoire: assessing their roles in EFL students' incidental vocabulary acquisition, Canada: Tesl Canada Journal.

E Jacobs, Gloria. (2008). We Learn What We Do: Developing a Repertoire of Writing Practices in an Instant Messaging World, New York: International Reading Association.

Haque, Shahzaman. (2011). Truncated Multilingual Repertoire in Indian Migrant Families in Three Cities of Europe, France: Universite Stendhal Grenoble III. Provided by ESUKAJEFUL:

$<$ http://www.ethnologue.com/show_ country.asp?name=IN $>$ primary source of all Indian languages cited here. Accessed September 08, 2008.

Helderman. (2006). Click by click, teens polish writing, Washington: The Washington Post.

Henry Guntur and DjagoTarigan. (1988). AnalisisKesalahanBerbahasa, Bandung: Angkasa.

Hornoby, A S. (2000). Oxford Learner's Dictionary: Oxford University Press.

Lee. C. (2005). How Does Instant Messaging Affect Interaction Between The Genders?. 
Ludi, Georges. (2003). Multilingual repertoire and the consequences for linguistics theory, New York: Lang.

Meyerhof, Miriam. (2006).Introducing Sociolinguistics, Ney York: The Taylor \& Francis e- Library.

Nugrahenny T.Zacharias. (2012). EFL Students' Understanding of Their Multilingual English Identities, Indonesia: SatyaWacana Christian University.

Paulina, Jones. (1996). Planning an Oral Language Program. In Paul Jones (ed). Talking To Learn. Melbourne: PETA.

Stockwell, Peter. (2007).Language and Linguistics the Key Concept $\left(2^{\text {nd }}\right.$ edition), New York: Routledge.

Puhl, Carol A. (1988).The Multilingual Person in Society. USA: PER LINGUAM, vol. 4 no. 2.

Sanggam, Siahaan. (2008). Issues in Linguistics, Yokyakarta: GrahaIlmu.

Spolsky, Bernard. (1998). Sociolinguistics, New York: Oxford Universities Press.

Sutanto Leo, et.al. (2007).English for Academic Purpose: Essay Writing, Jakarta: penerbitAndi.

Suu Kim, Lee, et.al.(2010). The English Language And Its Impact On Identities Of Multilingual Malaysian Undergraduates. GEMA online. Vol. 10(1).
Sweeney-Kerwin, Emily J. et.al. (2007). Transferring control of the Mand to the motivating operation in children with autism, Behavior Modification.

Wardaugh, Ronald. (2006). An introduction to sociolinguistics. United Kingdom: Blackwell Publishing. 